\title{
The value of a broad mind: some natural history meanderings of Bill Hamilton *
}

\author{
David Hughes \\ Department of Zoology, University of Oxford, South Parks Road, Oxford OX1 3PS, UK \\ (E-mail: david.hughes@zoo.ox.ac.uk)
}

Received 1 March 2002, accepted 16 May 2002

\section{BACKGROUND}

It has been remarked upon by Robert May (MAY 2001) that to write a paper with Bill Hamilton admitted one to a small circle, the honour of inclusion in which was not lost upon him. Equally, I think, a similar circle exits for people who can say they were students of Bill's. For a brief time I was co-supervised by Bill (and principally by Jeyaraney Kathirithamby). As his student I have found that I hold some imaginary identification card that allows me to garner information from numerous sources about various aspects of Bill's life. The esteem and reverence that so many biologists have for him guarantees that unsolicited emails requesting information are always answered if they begin with the line ... "I was a student of Bill Hamilton". The reason I should solicit information at all is that I am deeply fascinated by what exactly people mean when they speak of his "legendary knowledge" of the natural world (TRIVERs 2000). This essay is an attempt to document some of the natural history meanderings of Bill Hamilton. Such curiosity may be justified, as my own work (on peculiar parasites of social wasps) owes everything to a natural history episode of Bill's, which Luisa Bozzi, his partner for the last 6 years of his life, humorously related at a Social Insect Meeting in Florence, July 2000.

Luisa described an old abandoned house on a hill in Tuscany set among rolling fields of olive tress. Such a property appealed to her as a retirement home for them. However, Bill was increasingly nervous and uninterested in the idea. But his interest was greatly revived when he spotted that wasps had made their nest and examining close he found not only nests but also a very unusual aggregation on the blackberry bushes (Rubus spp.) that snaked through a broken window. What was unusual was not only the inactivity of these aggregating wasps but also the fact that most harboured a particular parasite. Correctly identifying it as an insectStrepsiptera, and supposing that its presence accounted for such unusual behaviour, he set about collecting the aggregations. Discussions of domesticity gave way to science and talk of retirement to parasite manipulation of host behaviour. Luisa could but follow! She remarked that many times a walk and conversation in the

* Presented at the W.D. Hamilton Symposium of the International Union for the Study of Social Insects conference, Berlin, July 2001. 
country with Bill would dramatically be broken off whilst he would hold aloft and remark on some example of life, only eventually returning in a convoluted to the original conversation.

\section{MEANDERINGS OF A NATURAL HISTORIAN}

FRANCIS RATNIEKS (pers. comm.) drew an analogy between CHARLES DARWIN's country walks along an "entangled bank ... [that offered] grandeur ... in this view of life" (1869: 579) with Bill's own observational nature. A large part my PhD work has attempted to understand the product of Bill's afternoon walk in Tuscany. During that time I have often thought that this episode could not be unique and that numerous other similar observations must have been made by him. It is clear from his papers, autobiographical writings (HAMILTON 1996, 2000, 2001), obituaries (ANGIER 2000, DaWkins 2000, Grafen 2000, Trivers 2000, Riberio 2000) and reminiscences by others, that he loved the natural world (see website: http://www.unifr.ch/ boil/ecology/hamilton/hamilton.html, maintained by an ex-student of Bill's, Dieter Ebert). But how did he amass his knowledge? We know that he was capable of gathering data when he studied his beloved fig wasps in Brazil (Hamilton 1979, 1996: 424) but for other times and groups of animals how did he proceed? Was he, as he claims, undisciplined in his observations, "compulsively following my own boyhood training" (HAMILTON 1996: 117) or does the occasionally self-deprecating writing style of 'My intended burial and why' mask a more rigorous approach in his observations of the natural world?

To me, an appreciation of the work of Bill Hamilton and its repercussions for evolutionary theory is aided by trying to understand the base upon which he built those ideas. The numerous examples, particularly of insects, which abound in his writings are not there to entertain (or frustrate those that are not "thoroughbredentomologists", HAMILTON 1996: 390), but rather they offer substance for his theoretical models. A case in point is his most famous work, "The genetical evolution of social behaviour I \& II" (HAMILTON 1964), which was submitted to the Journal of Theoretical Biology on the 13th May 1963 and resubmitted after revisions on the 24th February 1964. Between submission and revision he spent time at WARWICK KERR's lab in Rio Claro, Brazil where he made extensive observations on wasps and bees and these were included in Part 2 of the 1964 paper, because "I badly needed examples ... where both self sacrifice and the limits to it were indisputable" (HAMILTON 1996: 20).

\section{STREPSIPTERA AND SOCIAL WASPS, BRAZIL 1964-1968}

To investigate further the extent of his natural history meanderings I attempted to find out about Bill's association with my study organisms, Strepsiptera and social wasps. I knew that he had come across them previously as he wrote about them to Laura Beani, a researcher from the University of Florence who studies male mating behaviour in Polistes wasps and at whose house he was a guest when he and Luisa first discovered aggregations (L. Beani subsequently found aggregations and was instrumental in establishing, and continues, the study of strepsipteran ecology in Florence). Bill said, in an email to her on 3rd September 1998 that 
the aggregations reminded him of a similar phenomenon he had seen of "abundantly parasitized Polistes of a completely different species in a completely different continent [South America, Brazil] fussing around a very similar hibernacula [aggregation]". When I learned of this I was proposing to extend my study to the tropics but could not question Bill further as he was gravely ill at the time. Therefore, I contacted Mary Jane West-Eberhard and Bob Jeanne, two well known social wasp researchers in the tropics, and whilst both were very helpful they had little specific knowledge of the ecology of Strepsiptera in social wasps.

Following Bill's death I came to the conclusion that whatever information he knew, and hence was known, about this particular host-parasite system was to go with him. And then, a year later in the Natural History Museum of London whilst looking through their collections of Polistes wasps I came across some samples collected by Bill on the 1st August 1964 (his 28th birthday) which were clearly parasitized by Strepsiptera. No notes could be found pertaining to these and all that I could determine was the date of collection and location (Curacao, West Indies). I thought it possible that more information may be obtained from Bill's own notes, which I knew to be deposited in the W.D. Hamilton Archive at the British Library. This archive contains as much of Bill's work as has so far been able to be collected (see Summers \& Leighton John 2001) and is in the process of being catalogued by Jeremy Leighton John (an another ex-student of Bill's). He and Anne Summers (Curator of Modern Manuscripts) kindly acceded to my request to look through Bill's notes during the period in question, although this was not easy as the Archive was in its infancy. It is due to their kindness and enthusiasm, and to that of Bill's family, that I had the immense privilege to examine Bill's notebooks. The W.D. Hamilton Archive is still in the process of arrangement, such that individual items have not yet received their permanent Accession Numbers, and the archive is not yet available for scholarly consultation. Here I refer to original material through their sorting numbers, provided by Jeremy Leighton John.

In September-October 1963 Bill began an index card system on which he recorded species of wasps, bees and ants that he dissected during his first visit to Brazil. His question was "how Brazilian social wasps managed to keep their colonies cohesive and cooperating in spite of highly multiple egg-laying queens" (НAMILTON 2000: 117). Through a number of dissections he sought to find out; how many of the females on a nest were queens (as evidenced by developed ovaries), how many were inseminated and what state of development had the fat bodies attained. In some cases he also measured wing size and the number of hamuli (small hooks) on the wings; both features indicating caste. He did not restrict himself to social species but also examined solitary wasps and bees. These cards contain the details of 8 genera of wasps, 8 genera of bees and 2 genera of ants that he encountered and dissected. This amounted to a very large number of dissections. Concomitant notes in his journal of the time (W.D. Hamilton Archive, Sorting number: BL: Z1X55 17.1) detailed behavioural observations of Polistes wasps upon nests as well as results of staged encounters between queens taken into the laboratory. In one case he performed wing-clipping experiments to determine the effect this had upon dominance order. He recorded that he made field trips with staff members and communicated with Warwick Kerr for identification of samples as well as soliciting his opinion.

In reference to Strepsiptera, I noted that Bill saw aggregations of wasps, Polistes versicolor ("idle gatherings") on bushes (the century plant Agave americana) surrounding the university buildings. These wasps had not begun to nest on the buildings as many others had. He dissected these wasps and noted that the ovaries 
were not developed and some had parasites (identity not specified). The aggregations were noted from mid to late September 1963. I do not claim that the behaviour of these wasps was due to Strepsiptera but I am impressed by Bill's observations of two species of Polistes in aggregations from two continents separated by almost 30 years. To find specific references to Strepsiptera we need to look at his notes from the West Indies, 1st August 1964. He collected a number of nests (25) of Polistes versicolor from a wall surrounding a harbour. O.W. RICHARDS (1978) renamed this species as $P$. myersi curassivicus from the haplotype that Bill collected. Of these collected nests Bill dissected 6 (47 females and 2 males) and noted that 3 of the workers were parasitized by Strepsiptera. These were the specimens I had originally come across in the Natural History Museum, London. This time in the West Indies formed part of his circuitous route back to Britain via Canada when he was "weaving [his] old American jeep between corrugation, stones, and potholes of the Belem-Brasilia Road" and where he "stopped at the roadside and collected some wasps from some nests" (SEBASTIÃo LARAco pers. comm., HaMilton 1996: 29). In Goias State (16 June, 1964) he also came across Strepsiptera when he dissected a nest of Polybia singularis wasps. On the second trip he made to Brazil in 1968 he made many contributions to our knowledge of the ecology of tropical social wasps with pertinent observations of nest architecture, habitat selection, queen number and nest commensals, including Strepsiptera, as recorded by RICHARDS (1978). However, his interests were not confined to the social insects.

\section{THRIPS, BEETLES AND MITES, ENGLAND 1970-1972}

To see what other groups he studied we can jump to a time when he was in Imperial College, Silwood Park, England (notebooks 1970-1972 W.D. Hamilton Archive, Sorting Number: BL: Z1X55 17.4). Here, he studied members of subcortical communities of dead and rotting wood where "worms, mites, woodlice and insects of varied types were among my examples" and where he "worked with chisel, hammer ... and inevitably black-rimmed fingernails in Silwood Park and Windsor Forest" (HAMILTON 1996: 389-390).

By 1970 he had published his papers on Kin Selection (1964), Senescence (1966), Extraordinary Sex ratios (1967) and Spite (1970). His 13 year period at Silwood, at least judging from his notebooks of 1970-1972, were a mixture of theoretical work and natural history observations. "Today was remarkable for two reasons [climbed an Oak tree, removed a branch] ... exposed a damp, mouldy dark chestnut layer on which thrips were crawling in great number". The first reason alluded to was a short note stating a favourable simulation of some model relating to the issue of haplodiploid males on which he working at the time and the second reason was his discovery of thrips. The latter were to become increasingly important to him in thinking about the enclosed spaces afforded by dead tree habitats and factors favouring sociality (HAMILTON 1978). Thrips (order Thysanoptera) are, like the Hymenoptera, haplodiploid and it seems that this prompted Bill to ask if they display behaviour similar to the social Hymenoptera. The genus he focused on, $\mathrm{Ha}$ plothrips, lived in cavities of rotting wood where they fed upon abundant fungus (Stereum spp.). To facilitate observation he collected dead wood and removed them to the lab (even recording in his notes that he collected suitable wood whilst on a camping holiday with his family in East Anglia, England). This involved a lot of 
tree climbing for which he was rather famous (see Shigeyuki Aoki's essay on the Bill Hamilton web site).

Bill wrote: "I am afraid my general impression is that there is a very definite weird life: the best one can say is that thrips do not avoid one another", "Again I was disappointed to see no sign of a social reaction between the slowly wandering adults and their larvae or between larvae or between adults" W.D. Hamilton Archive, Sorting Number: BL: Z1X55 17.4.

His search for social behaviour among the thrips was eventually satisfied when he and Bernard Crespi watched "gladiatorial looking thrips" (HAMILTON 1996: 428). At the time (University of Michigan) he served on the doctoral committee of B.J. CRESPI who recalls (pers. comm.) how they observed fighting in American $\mathrm{Ha}$ plothrips and Elaphrothrips that have a fighter-flier polymorhism in males. CRESPI continued the work and found what Bill was initially searching for; truly eusocial thrips, in the sub-order Tubulifera. These were in acacia galls of the Australian bush and of the six species so far discovered to display eusocial behaviour he named one after Bill, Kladothrips hamiltoni (see Mound \& CRESPI 1995, KRANZ et al. 1999). Whilst varying degrees of eusociality appears, now, to be found among many diverse groups (e.g. Hymenoptera, Isoptera, aphids, spiders, Acari, thrips, shrimps and mole rats) only the first two instances were known in 1970 when Bill was chiselling away at tree branches in search of it. His 1964 paper clearly predicted that eusociality in thrips should exist, yet in the absence of data in the literature he was forced to go searching himself, not the actions of a typical theoretical biologist!

Also at this time, he was interested in beetles living in dead tree communities, such as Ptinella (feather- wing beetles) and Xyeleborous (bark beetles). "Today I took my lunch over to the wood and discovered that a big beech tree ... had fallen recently ... and should provide an excellent further habitat for colonisation by Xyeleborous, Stereum, Haplothrips and so on", "Last Thursday (23.IX.1971) I ate my sandwiches by the fallen beech top ... and found abundant Scolytid activity ... Xyeleborus was really abundant". To study Xyeleborus he would collect branches in which colonies of these bark beetles had excavated galleries and then rear them out to determine

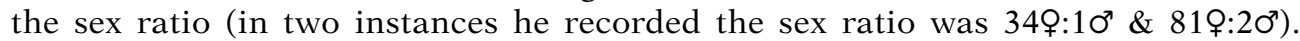
These reflect Hamiltonian sex ratio frequencies under local mate competition (HAMilton 1967). In some circumstances the sex ratio may be biased towards an almost exclusively female brood with the barest minimum of investment in males. These males, through sib-mating, fertilise the females who later depart. Indeed, lab observations by Bill recorded how the males would guard the entrances to the galleries (presumably against other males). Regarding the sex ratios which he found he said, "indeed it was as if in return for the affection and curiosity I paid to them, they kindly agreed to fit quantitative theories more closely than a population or evolutionary biologist normally dares hope for." (HAMILTON 2000: 118).

The other species of beetle he observed (Ptinella) is analogous to the strepsipteran story in that it turned into a PhD subject by VictORIA TAYLOR. Bill kept cards upon which he made observations of Ptinella (V. TAYLOR pers. comm.) and decided to encourage a student to investigate the full story of its sub-cortical life (TAYLOR 1978; HAMILTON 1996: 386, 2001: 13). Of further interest among his notes are observations on phoretic mites associated with Ptinella and the Stereum communities. What these mites were was not recorded, but I fancy they were Pygmephorus, which is an exceptional creature and the most amazing example of Bill Hamilton's natural history meanderings. This mite lives under bark where it feeds upon Stereum fungus, once gravid the female becomes greatly enlarged with devel- 
oping young (see author's picture: HAMILTON 1996: 130). These are almost exclusively female with one or two males walking around inside its mother's womb mating with its sisters! The mother eventually bursts and the polymorphic females (which unlike their mother have enlarged tarsi) ride of on suitable beetles to colonise new patches. In his usual style Bill dubbed it "incestuous love making by babies within the womb" (2001: 19). I think that our knowledge of Pygmephorus is limited to the brief mentions he made of them in his writings (e.g. HAMILTON 1979), as I can find no reference to it's ecology elsewhere. Surely, as with the story of Ptinella, this would have been a wonderful PhD topic. Yet, as I write, it becomes clear that an army of students would have been needed to follow the paths of Bill's natural history walks. How far he went on these walks is a topic of great interest, though for the present I shall leave it here, but just point the direction for future investigations, many of which are recounted on the Bill Hamilton web site. He observed butterflies and ergatoid males of Caridocondyla wroughtonii in Japan with Yosiaki Itô, climbed yet more trees whilst collecting soldiers of gall forming social aphids (see AoKI et al. 1977) with Shigeyuki Aoki, Naomi Pierce \& Andrew Berry in Taiwan and searched temporary pools of the flooded forest of the Amazon with Peter Henderson (another ex-student of Bill's). To gain a greater knowledge of him as a supervisor and field companion one might do well to look at the recollections of his last Brazilian student, SÉRVIo P. RIBERIO (2000).

\section{CONCLUDING REMARKS}

I knew Bill for only a short time. If I claim any familiarity and understanding of his character, it is through the many stories and reminiscences of others, as well as his own writings. By far the most significant of these stories was one related by Michael Worobey at Bill's funeral. Michael, with Jeffery Joy, accompanied Bill on his last expedition to the Congo (see Summers \& John 2001). Bill had an old and well-worn machete that he set about sharpening for their impending trip. Michael and Jeff bought new and shiny ones which they thought must be better that Bill's. However, after a few hours in the thick undergrowth of the jungle the plastic handles broke and they were forced to walk behind Bill as he cut the path through the forest. Michael drew an analogy with Bill's career; he cut a lonely, paradigmshifting path through science which others would follow. He used natural history as a tool in much the same way he used his machete on his last field trip. Perhaps in this short essay I have been able to describe some aspects of this tool and his amazing familiarity with it. Whether I have succeeded or not, it is clear that his "incurable fascination" with the natural world aided in the formulation and substantiation of his ideas. Whilst few are lucky enough to have such ideas we can at least console ourselves in the knowledge that a broad mind, borne of an appreciation of natural history, is the key, however few and little our ideas may be.

\section{ACKNOWLEDGEMENTS}

I warmly thank those that responded to my requests for information: Prof. Shigeyuki Aoki (Rissho University, Japan), Dr Laura Beani (University of Florence, Italy), Prof. Bernard Crespi (Simon Fraser University, Canada), Dr Ruth Hamilton (Cambridge University, UK), Prof. Yosiaki Itô (Nagoya University, Japan), Prof. Robert Jeanne (University of Wisconsin- 
Madison, USA), Dr Brenda Kranz (Tokyo University of Agriculture, Japan), Prof. Sebastião Laraco (Curitibá, Brazil), Prof. Naomi Pierce (Harvard University, USA), Miss Christine Taylor (British Museum of Natural History, UK), Dr Victoria Taylor (Imperial College, UK), Prof. Mary Jane West-Eberhard (University of Costa Rica). I thank Dr Jeyaraney Kathirithamby (University of Oxford, UK) for introducing me to Bill and Prof. Alan Grafen (University of Oxford, UK) for encouraging me to speak at the IUSSI symposium on Bill Hamilton, as well as the organisers, Prof. Francis Ratnieks (Sheffield University, UK) and Prof. Koos Boomsma (University of Copenhagen, Denmark), for allowing me. I warmly thank Bill's family, as well as Dr Jeremy Leighton John and Dr Anne Summers (British Library, London, UK) for access to Bill's notebooks. I thank Dr L. Beani, Dr Mary Bliss (London, UK), Dr Luisa Bozzi (Turin, Italy) and Dr J. Leighton John for critical reading and suggestions on an earlier draft. Finally, I owe a great debt to Dr L. Beani who has thought me so much about Bill Hamilton and human nature. I was supported by the IUSSI (British Section) and Jesus College, Oxford.

\section{REFERENCES}

ANGIER N. 2000. Obituary. The New York Times, 10th March 2000, New York.

Aoki S., Yamane S. \& KUichi M. 1977. On the biters of Astegopterx styracicola (Homoptera: Aphidoidea). Kontyû 45: 333-337.

DaWKINS R. 2000. Obituary. The Independent, 10th March 2000, London.

DARWIN C. 1869. The origin of the species, 5th Edition. London: John Murray.

Grafen A. 2000. Obituary. The Guardian, 9th March 2000, London.

Hamilton W.D. 1964. The genetical theory of social evolution I \& II. Journal of Theoretical Biology 7: 1-52.

Hamilton W.D. 1966. The moulding of senescence by natural selection. The Journal of Theoretical Biology 12: 12-45.

HAMILTON W.D. 1967. Extraordinary sex ratios. Science 156: 477-488.

Hamilton W.D. 1970. Selfish and spiteful behaviour in an evolutionary model. Nature 228: 1218-20.

HAMiLton W.D. 1978. Evolution and diversity under tree bark, pp. 154-175. In: Mound L.A. \& Waloff N., Edits. Diversity of insect faunas. Symposia of the Royal Entomological Society of London No. 9. Oxford: Blackwell Scientific.

Hamilton W.D. 1979 Wingless and fighting males in fig wasps and other insects, pp. 167-220 In: Blum M.S. \& Blum N.A., Edits. Reproductive competition, mate choice and sexual selection in insects. New York and London: Academic Press.

HamiLton W.D. 1996. Narrow roads of gene land, Vol. 1. Oxford: Oxford University Press.

Hamilton W.D 2000. My intended burial and why. Ethology Ecology \& Evolution 12: 111-122. (Originally published, in Japanese, in the Insectarium 28: 238-247 with 20 photos taken by the author).

Hamilton W.D. 2001. Narrow roads of gene land, Vol. 2. Oxford: Oxford University Press.

Kranz B., Schwarz M.P., Mound L.A. \& Crespi B.J. 1999. Social biology and sex ratios of the eusocial gall inducing thrips Kladothrips hamiltoni. Ecological Entomology 24: 432-442.

MaY R. 2001. Memorial to Bill Hamilton. Philosophical Transactions of the Royal Society of London (B): 785-787.

Mound L.A \& CRESPI B.J. 1995. Biosystematics of two new species of Australian Acacia gallthrips with soldiers. Journal of Natural History 29: 147-157.

RIBERIO S.P. 2000. Obituary. Antenna 24 (3): 119-121.

RICHARDS O.W. 1978. The social wasps of the Americas excluding the Vespinae. London: British Museum (Natural History).

Summers A. \& Leighton John J. 2001. The W.D. Hamilton Archive at the British Library. Ethology Ecology \& Evolution 13: 373-384.

TAYLOR V.A 1978. A winged elite in a subcortical beetle as a model for a prototermite. Nature 276: $72-75$.

Trivers R. 2000. Obituary. Nature 404: 828. 